Arab World English Journal (AWEJ) Volume 12. Number4 December 2021

DOI: https://dx.doi.org/10.24093/awej/vol12no4.13

\title{
Effects of an In-house Entry Test on the Post-Foundation Students at an Omani College of Technology
}

\section{Sarath W. Samaranayake}

Department of International Language Teaching

Silpakorn University, Nakhon Pathom, Thailand

Corresponding Author: Samaranayake_s@su.ac.th

\section{Patteera Thienpermpool}

Department of International Language Teaching

Silpakorn University, Nakhon Pathom, Thailand

Received: 10/29/ 2021

Accepted: 11/11/2021

Published: 12/15/2021

\section{Abstract:}

This paper reports the findings of a study that investigated why a large number of test-takers show a low performance in four language skills (listening, speaking, reading, and writing) offered in an entry test used by a College of Technology in Oman to place students in advanced diploma and bachelor's degree programs. The main research question was meant to find out what difficulties the test takers face in the three tests (Listening, reading, and writing) in two semesters. The study analyzed the entry test results for two semesters including survey results obtained from the test takers regarding the difficulties experienced by them in the three tests and an analysis of writing answer scripts. The findings indicate that most test takers were not qualified enough to pursue their studies in the advanced diploma or bachelor's degree programs due to their low performance in the entry test. The findings, moreover, suggest that the current placement test poses difficulties for most test-takers. Therefore, based on the findings, the possible reasons for the low performance of the test takers and the fairness of the entry test are explicitly discussed and finally, suggestions and recommendations for addressing the issue of the current entry test are offered.

Keywords: Foundation programs, Low performance, Omani learners, Placement test, Proficiency level

Cite as: Samaranayake, S. W. (2021). Effects of an in-house entry test on the Post-Foundation Students at an Omani college of technology. Arab World English Journal, 12 (4)

DOI: https://dx.doi.org/10.24093/awej/vol12no4.13 


\section{Introduction}

The Colleges of Technology in Oman come under the purview of the Ministry of Manpower and they are one of the higher education institutions that conduct professional courses leading to a certificate, diploma, higher diploma, and bachelor's degree in Engineering, Business Studies, and Information Technology. Seven colleges have been strategically established in different provinces to provide Omani youths with education and training facilities that will help them to become skilled professionals in their chosen field of specialization in the future. The study programs at the Colleges of Technology (CoTs) allow students to pursue their studies beyond certificate and diploma levels provided that they meet the language proficiency level required in the post foundation. For the students to be placed in the advanced diploma and bachelor's degree programs, a placement test (In-House Entry Test) is conducted every semester and students should receive a band 4-four to be eligible to study in the advanced diploma level while a band 4.5 is required to study in the bachelor's degree program as per the notice issued in connection with the student placement in the post foundation programs by the Ministry of Manpower (MoM). In-House Entry Test (IHET) consists of three test papers (listening, reading, and writing) excluding speaking and these papers are prepared by a specialized committee established at the Higher College of Technology (HcT), Muscat, and delivered the examination papers to the other six colleges each semester. Given the importance of higher education at the colleges of technology, In-House Entry Test (IHET) plays a key role in that it decides whether a student can pursue his/her education beyond the certificate level or end at the certificate or diploma level. The colleges of technology conduct the IHET examination for the students who are eligible to take the test and release the results to the respective candidates. However, at the college level, there is no specific training course offered for the students intending to sit for the IHET except advising students to refer to the college website which provides test takers with learning materials and guides relevant to the IELTS exam (English Language Magazine, 2016, p. 21).

Even though, the scenario of the current IHET remains undebated, it seems to have pernicious effects on the college level students who want to pursue their studies in higher education because many test-takers either fail or show low performance in the exam every semester. Thus, the IHET remains a barrier for most students who complete their diploma courses in their chosen specializations (Annual Report of ELC, 2016). As a result, they do not qualify to enter the advanced diploma or bachelor's degree programs in their specializations. Oman is one of the Gulf countries that suffers a shortage of skilled and experienced labor force. Oman Daily Observer has reported that Oman currently hosts nearly 1.8 million expatriate workforce while 14,000 Omanis are looking for jobs ("Expatriate Must to Meet Skill Shortage," 2014). When the country has faced such a huge skill labor shortage, depriving the higher educational opportunities of Omani youths for want of mere English language competency can be unfair. Given the context stated above, the current study aims to address what negative effects are experienced by the post foundation students at this college of Technology where the researcher worked for five years, in particular, and the other six colleges of technology in general. 


\section{Literature Review}

It is an undebatable fact that students wishing to pursue their higher studies in a local or international educational institution should have a requisite English language proficiency level to meet the linguistic demands imposed by the respective study programs. To this end, most universities in English-speaking countries demand that students seeking admission to those universities should have an IELTS band or TOFLE scores to be included in a particular study program a student has applied to.

The demand for higher education delivered in the medium of English has increased dramatically in the past few decades. At present, it is evident that not only the number of international students seeking admission to study in English-speaking countries are on the rise but also the English-medium universities established in non-English speaking countries, particularly in the Middle East (Wait \& Gressel, 2009). Such universities have relied on international tests of English language proficiency, such as IELTS and TOEFL to assist in making decisions relevant to the language proficiency of the applicants. However, these tests have no 'passing' scores. Therefore, higher education institutions are left to make their judgments about the level of English language proficiency that international students must demonstrate to be admitted to a particular study program an applicant has applied for. Various studies have investigated issues related to the IELTS exam as an entry test in different teaching contexts across the world and most of them found that students faced difficulties in getting a required band to be qualified for admission in a higher education institution either locally or internationally (Bellingham, 1993; Philips, 1990; Shaw, 2000). This study will not discuss the pros and cons of IELTS as an entry test in a broader sense. However, it attempts to evaluate how fair is the entry test given to the test takers of the colleges of technology to place them in either higher diploma or bachelor's degree programs (Engineering, Business Studies, and Information Technology) which is not related to their chosen specialization field. The following section will describe the research problem which will be followed by the research question.

\section{Research Problem}

The annual report compiled by the English Language Centre (ELC) in 2015-2016 of this College of Technology (Annual Report of ELC, 2016) includes statistics about all examinations conducted by the center. This report indicated that the performance of the test-takers in the InHouse Entry Test (IHET) was far below the expected standard levels in the three skills (Listening, reading, and writing). Moreover, the researchers, who happened to work as invigilators and assessors of IHET for the last four years, observed that some students did not understand the written questions clearly in that they tended to ask the invigilators for an explanation. A condition of this nature can be ascribed to irrelevant cognitive barriers to the performance of test-takers. According to ETS International Principles for the Fairness of Assessment (2016, p. 5), "Unfair barriers may occur when knowledge or skill not related to the purpose of the test". As noted above, when the In-House Entry Test remains as an unfair barrier for most test takers of the colleges of technology in Oman, a news report published in the Times of Oman in 2016 says that more than 10,000 students dropped out of colleges during the academic year 2014-15 ("Oman-education," 2016). The data was quoted from the Higher 
Education Admission center. Even though the report stated that personal issues were the most common reason for dropping out of college, students' difficulty to cope with the education level they confront in higher education institutions nowadays has been emphasized as a specific reason. Given the specific reason as stated above, it can be assumed that there can be some effects of examination systems administered in the colleges of technology on college students' dropout.

Given the condition described above, the researchers decided to investigate why most test-takers fail or show low performance in the IHET, what difficulties they face in the three tests (Listening, reading, and writing), and how this problem can be addressed to minimize the failure rate in IHET. With the premise that investigating the IHET and its impact on the test-takers will help researchers to suggest ways and means to address the problems relating to IHET, the following research question was formulated.

\section{Research Question}

1. Did the test takers find the three tests (Listening, reading, and writing in IHET difficult in both semesters?

It is evident that past research which investigated the results of different types of entry tests including IELTS conducted in tertiary level education institutions suggest that the test results of the test-takers in both English speaking and non-English speaking contexts (Arrigoni \& Clark, 2015; Breeze \& Miller, 2011) in general are not positive. Therefore, based on the premise stated above, the following hypothesis will be investigated in the current study.

\section{The Purpose of the In-House Entry Test}

The colleges of technology use the IHET to place post foundation students in the advanced diploma and bachelors' degree programs where students should receive a band of 4 or 4.5 to be placed in an advanced diploma or a bachelor's degree program respectively. Each of the colleges of technology conducts the IHET as a part of their study programs every semester.

\section{The Structure of the In-House Entry Test}

As per the details included in the college website (http://www.shct.edu.om/content/houseentry-test), the test takers for the IHET should be second-year diploma and advanced diploma students studying in semesters 2 and 3 in their specializations. The test papers of the IHET are prepared by a specialized committee set up at the Higher College of Technology (HcT) in Oman and delivered the testing materials to other colleges of technology (CoTs) at the beginning of every semester specifying the exam dates and times. The listening, reading, and writing tests of the IHET are assessed by the English language lecturers of the respective colleges using the answer keys (Listening and reading) and writing rubrics issued along with the exam guides by the HcT. When assessing the answer scripts of IHET, double marking is used to ensure the reliability of the results.

The IHET consists of three parts that intend to measure students' abilities in three skills (listening, reading, and writing) excluding speaking skills. These three skills are tested within 80 
minutes in which listening and reading are allocated 20 minutes each while 40 minutes are given to answer one question in writing. The listening test has 15 questions with two parts. In part 1, test takers are required to listen to a conversation and a lecture or a part of a lecture and select the correct answer from the options given and in part 2, test-takers listen to a lecture and complete some notes in the outline provided with no more than three words or numbers. Other specific instructions for listening include that the recordings are heard only once, spelling mistakes are penalized, and 5 minutes are given at the end of the listening test to transfer their answers to answer sheets.

The reading test is comprised of one passage with 15 questions with three test types which should be answered in 20 minutes. The writing test includes one topic which should be attempted in 40 minutes with 250 words. Test takers are supposed to write a discussion essay or an argument essay about the topic provided.

The information included in the college website, moreover, states that the test takers should be familiar with the IELTS Academic Module 2 since the task type and format of the writing question in the in-house entry test is similar to IELTS Academic Module Task 2 (http://www.shct.edu.om/content/house-entry-test).

\section{Objectives of the Research}

By conducting this research, the researchers hope to achieve the following objectives:

1) To investigate whether the IHET was difficult for the test-takers in both semesters.

2) To suggest possible measures that can be used to address the problems of the current IHET.

\section{Research Methodology}

The research was conducted using the quantitative method in which a quantitative framework, more specifically a quasi-experimental design was used. The data for analysis was obtained from two In-house Entry Tests, a survey questionnaire, and an analysis of 48 writing answer scripts selected randomly from two in-house entry tests. The answer scripts were analyzed for quality (see below for more information) because the writing was marked subjectively using rubrics while listening and reading answer scripts were not needed to analyze since they were marked objectively. The questionnaire included two sections: the first section was meant to obtain information relating to how they fared in the tests (Behavioral questions, Dörnyei, 2007) while section B dealt with some attitudinal questions which asked participants to tell how they should be supported in the IHET. The questionnaire was sent to 150 test takers who appeared for IHET during the first and second semester respectively and their responses were quantitatively analyzed to determine whether their low performance in the test had resulted due to the difficulty level of the test or their inadequate knowledge of the language skills and insufficient training for the test.

\section{Questionnaire}

The researchers developed the questionnaire which included two parts. In the first part, the researchers wanted to find out how the participants fared in the three tests (Listening, reading, 
and writing) in IHET. Therefore, part 1 carried closed-ended 20 items which were designed in line with the Likert Scales and meant to elicit how and what they exactly did to get the scores reported in the three tests. Part 1 included items relating to listening, reading, and writing skills while part 2 included 6 closed-ended items which were meant to elicit their ideas and opinions (attitudinal questions) about how the English Language Centre (ELC) should help learners perform better in the three tests in IHET. The participants for the survey questionnaire were selected using a random purposive sampling technique (Laerd Statistics, n.d.; Onwuegbuzie \& Leech, 2007). The questionnaire was distributed among 150 participants who were selected as follows: every sixth participant from each group (each group consisted of 30 students) was selected from 30 groups that took the IHET test during the first and second semester of 2016-17, totaling 150 participants. The completed questionnaires were received, and they were analyzed quantitatively to determine whether there was a link between the test takers' behavior in the test and the results.

\section{Examination of Marked Writing Answer Scripts}

Tayler (2004) has argued that by analyzing actual samples of writing performance, we can understand more about key features of writing ability across different proficiency levels and within different domains. As Tayler (2004) has observed, the researchers analyzed 48 samples of writing scripts drawn from the IHET exam conducted in the second semester to understand better of writing performance of test-takers. 48 samples of marked writing answer scripts were selected (three from each) from 16 groups and they were analyzed qualitatively using T-Unit analysis (Elola, 2005; Larsen-Freeman, 1978). Specifically, the quality of writing was established using an error-free T-unit ratio (EFT/T) (in which the EFT/T is calculated as the total number of errorfree T-units in a given piece of writing divided by the total number of T-units) (Wolfe-Quintero, Inagaki, \& Kim, 2001). This analysis helped the researchers to decide the extent to which the test takers' rating in the questionnaire for the writing task was similar or different. To prevent gender bias, marked writing answer scripts were drawn from both male and female students who sat for IHET in the second semester of the 2016-17 academic year. However, it should be noted that no marked answer script was selected for qualitative analysis from the first semester IHET exam because the researcher felt that analyzing 48 marked writing answer scripts from the second semester would be enough to understand how they fared in the writing test. Three marked writing answer scripts were drawn from each group based on the scores ranging from the highest, middle to the lowest, and they were re-checked against the writing marking criteria without allocating any mark.

\section{Participants of the Study}

The participants in the current study were second-year diploma and advanced diploma Omani students studying in semesters 2 and 3 in their specialization programs in the post foundation level during the academic year of 2016-2017. These students were between the ages of 20 and 23 and were both male and female and they had already studied the foundation level English program which consists of speaking, listening, reading, grammar, and writing for 4 semesters. Therefore, it is assumed that the students who study in the second-year diploma and 
advanced diploma programs will have adequate English proficiency in the four skills to function well in the post foundation programs in which the students are required to study their specialization programs in English.

\section{Findings Related to the Research Question}

The research question concerned with whether test-takers find the three tests (listening reading, and writing) difficult in the IHET in two semesters of 2016-2017. To find out the test takers' performance during the two semesters, the researchers analyzed the test takers' marks for the three tests. The number of test-takers and the scores they obtained in each test for two semesters are illustrated in the figures (1-6) below.

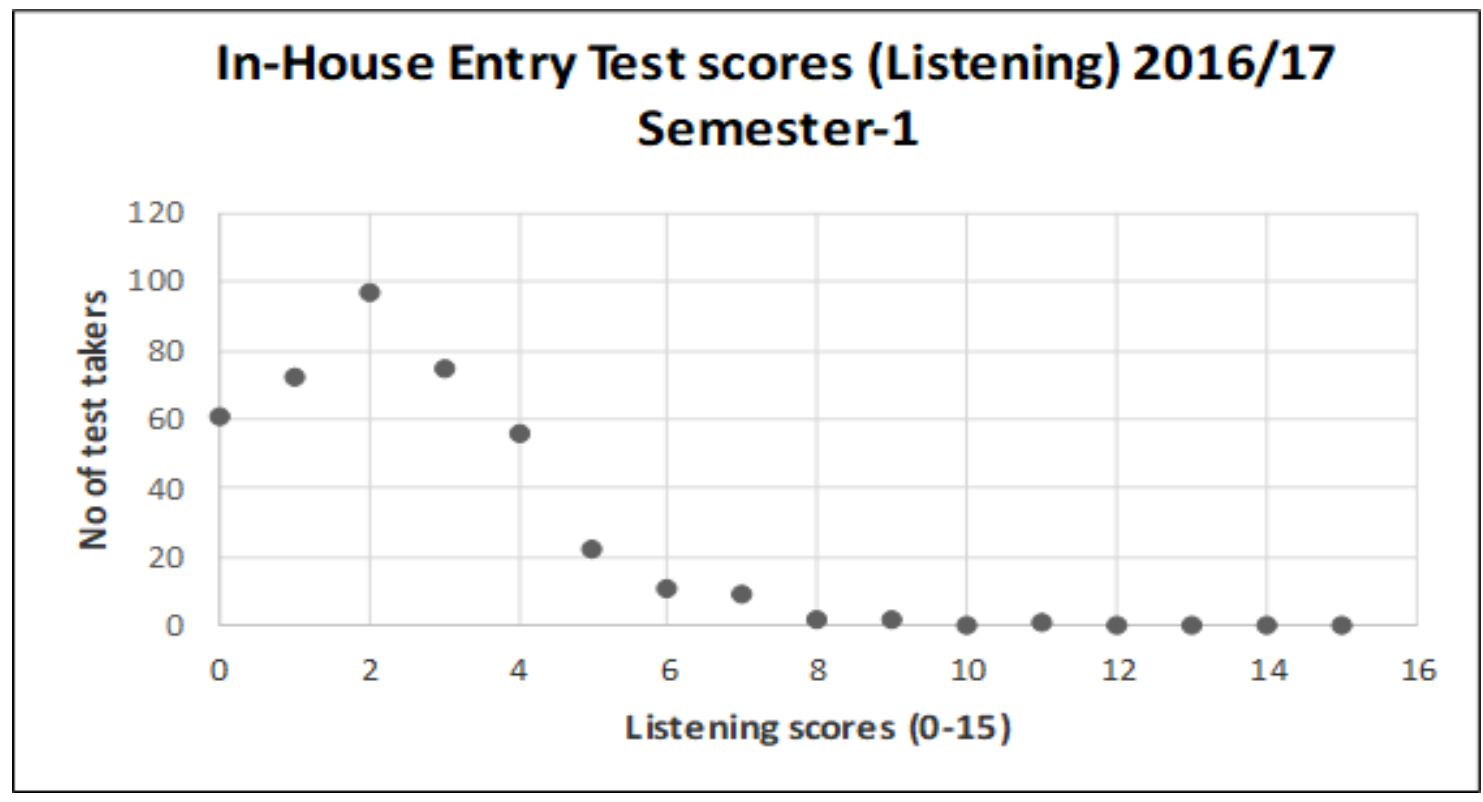

Figure 1. In-House Entry Test results for listening skill in the first semester of 2016/17 As shown in Figure 1, 408 test-takers from 14 groups appeared for the IHET in the first semester (September-December 2016) and each group consisted of 30 test-takers except one group which had only 18 students. 14 percent scored a 0 on the listening test, while 17 percent scored a 1 . Out of all listening test-takers, 22 percent scored a 2, whereas 18 percent scored a 3 . 13 percent scored a 4 while 5 percent scored a 5 . Only 2 percent scored a 6 and a 7 while 0.4 percent scored an 8 and a 9 , but no test taker scored a 10. However, 0.2 percent scored an 11, but no candidate scored a 12 , a 13 , or a 15 in the listening test. 


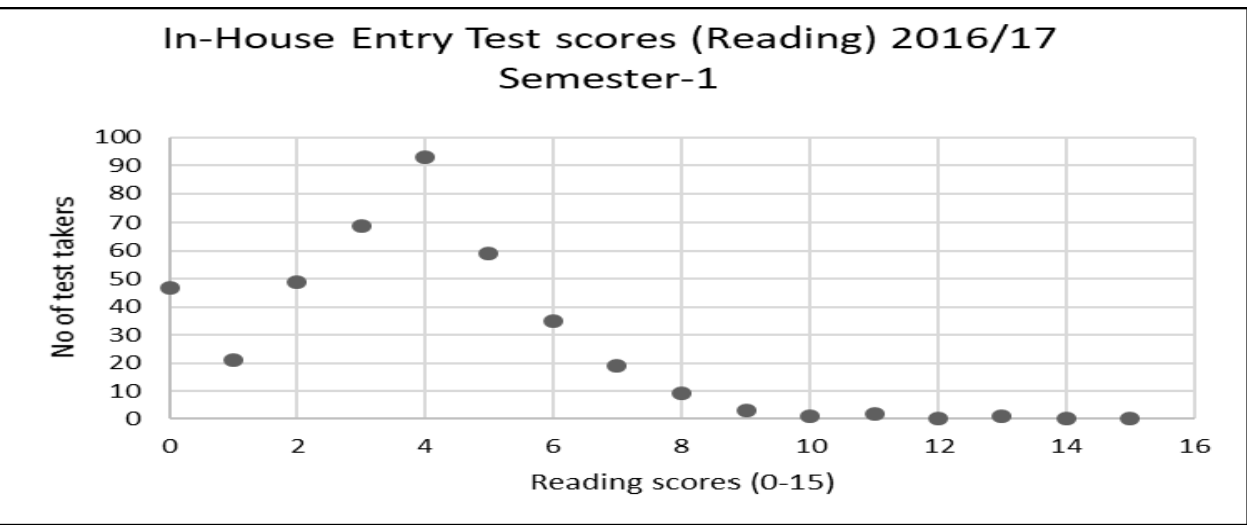

Figure 2. In-House Entry Test results for reading skill in the first semester of 2016/17

In terms of reading as illustrated in Figure 2, 11 percent scored a 0 and 5 percent scored a 1 out of 15 for the reading test. 12 percent scored a 2 while 16 percent scored a 2 , but 22 percent could score a 4 . Meanwhile, 14 percent scored a 5 and 8 percent could score a 6 . However, 4 percent scored a 7 and 2 percent scored an 8 indicating a downward trend. Only 4 percent of test-takers scored a 7 while 2 percent scored an 8.0 .7 and $02 \%$ scored a 9 and a 10 respectively, but no test taker scored a 12 . Finally, 0.2 percent scored a 13 with no candidate scoring a 14 or a 15 for the reading test.

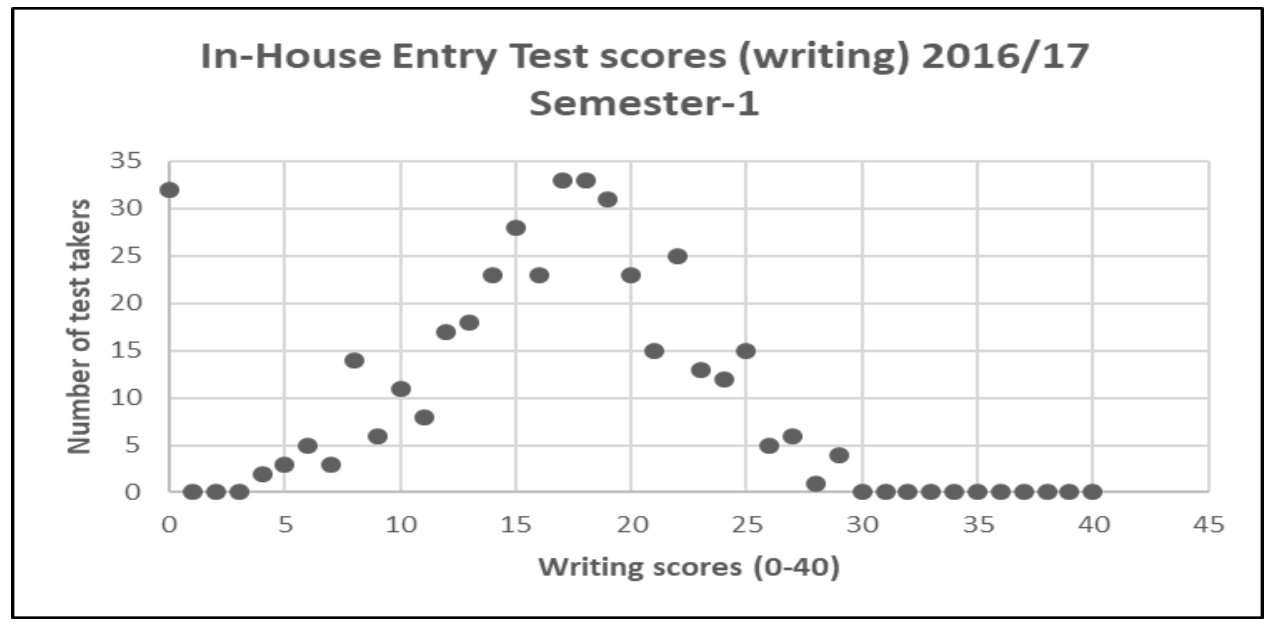

Figure 3. In-House Entry Test results for writing skill in the first semester of 2016/17

When it comes to writing, Figure 3 indicates that 7 percent scored a 0 and no test taker scored a 1 to 3 in the writing test. 0.4 percent scored a 4 and 0.7 percent scored a 5 , but 1 percent scored a 6. Moreover, 0.7 percent scored a 7 and gradually rose to 3 percent which scored an 8 . When it came to a 9 score, the percentage was only 1.2 percent scored a 10 while 1 percent scored an 11 . 
4 percent scored a 12 and 13, but only 0.7 percent scored a 14 . However, 6 percent of test-takers out of 408 scored a 15.5 percent scored a 16 and the percentage for the scores 17 and 18 was 8 . However, 7 percent scored a 19 while 5 percent scored a 20 and then the percentage fell to 3 where the score was 21.6 percent scored a 22 while 3 percent scored a 23, but only 2 percent scored a 24 . However, when it came to a 25 , the percentage rose to 3 and then onwards, a fall in percentage can be observed. 1 percent could score a 26 and 27, whereas 0.2 percent scored 28 and 0.9 percent scored a 29 indicating the highest score for the writing test out of 40 . No test taker scored 30 to 40 with no percentage to be recorded.

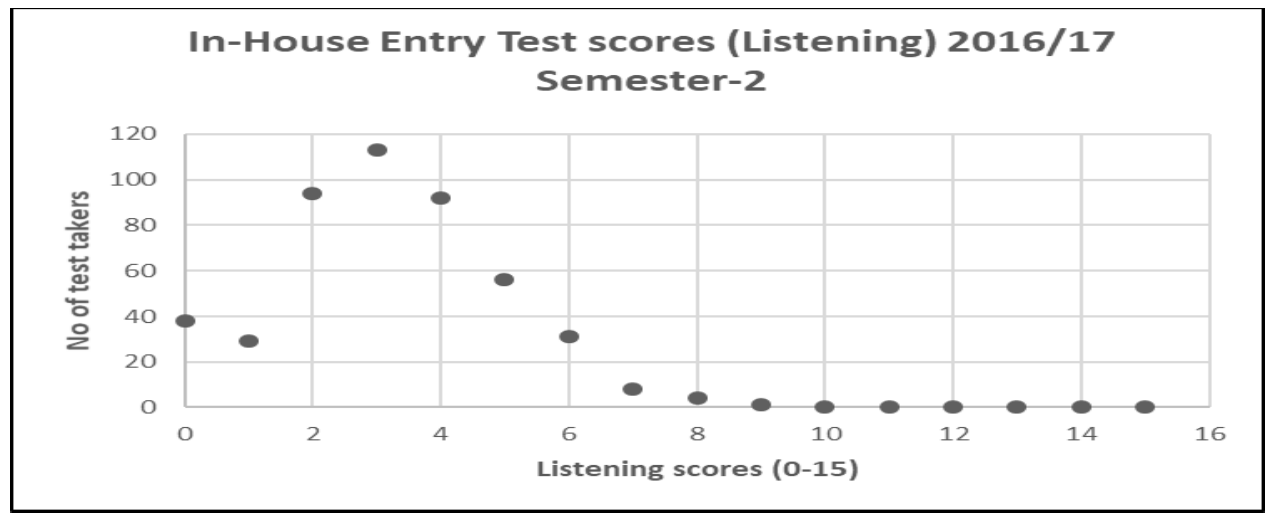

Figure 4. In-House Entry Test results for listening skill in the second semester

As shown in Figure 4 above, 466 test-takers from 16 groups sat for the In-House Entry Test during the second semester (January - April 2017) and each group consisted of 30 test-takers except two groups in which there were 29 and 17 students respectively. According to the test results, 8 percent scored a 0 on the listening exam, while 6 percent scored a 1 . Out of all listening test-takers, 20 percent scored a 2, whereas 24 percent scored a 3. 19 percent scored a 4 while 12 percent scored a 5 . Only 6 percent scored a 6 and 1 percent could score a 7 while 0.8 percent scored an 8 , but only 0.2 percent scored a 9 . However, no candidate scored a 10 or beyond 10 .

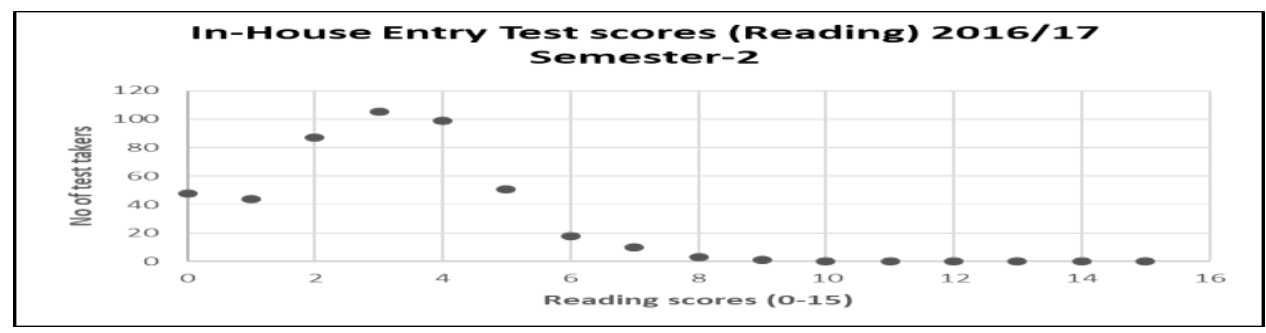

Figure 5. In-House Entry Test results for reading skills in the second semester 
In terms of reading as illustrated in Figure 5, 10 percent scored a 0 and 9 percent scored a 1 out of 15 for the reading test. 18 percent scored a 2 while 22 percent scored a 2.21 percent could score a 4 .

Meanwhile, 10 percent scored a 5 and 3 percent could score a 6 . However, 2percent scored a 7 and 0.6 percent scored an 8 indicating a downward trend. Only 0.6 percent of test-takers scored an 8 while 0.2 percent scored a 9 and no test taker scored a 10 or beyond 10 as was done in the listening test.

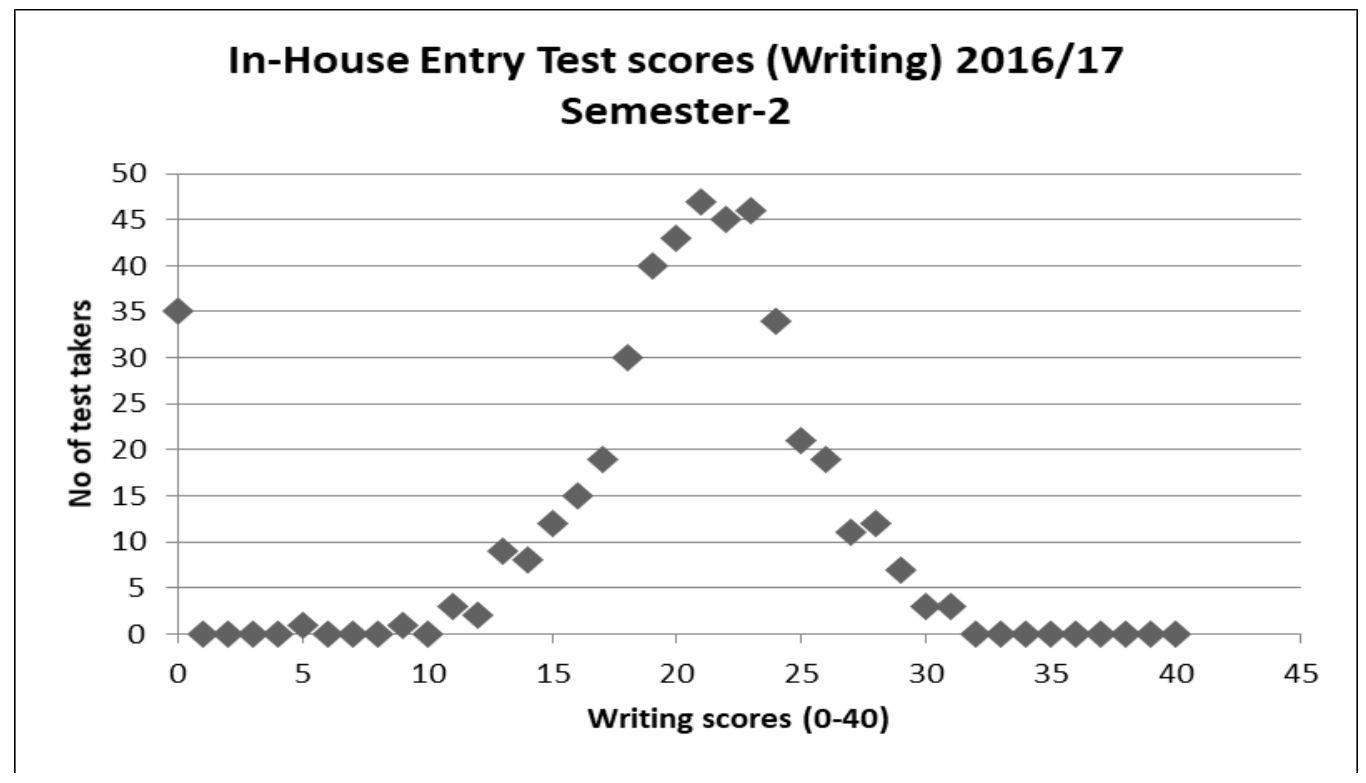

Figure 6. In-House Entry Test results for writing skill in the second semester

As indicated in Figure 6, in terms of writing, 7 percent scored a 0 and no test taker scored a 1 to 4 in the writing test. 0.2 percent scored a 5 and 9 while 2 percent scored an 11 , but 0.4 percent could score a 12. Moreover, 1.9 and 1.7 percent scored a 13 and 14 respectively. From 3.4 to $10 \%$ showed a gradual rise in scores. 2.5 percent scored a 15 and 3.4 a 16 while 4 percent scored a 17. 6.4 could score an 18 and 8.5 a 19 . When it came to a 20, there was 9.2 percent while 10 percent scored a 21. From then onward, a gradual decline of scores was indicated. 9.6 percent scored a 22 and 9.8 a 23, but 7.2 percent scored a 24, whereas 4.5 percent scored a 25 while 4 percent could score a 26. When it came to a 27 and a 28 , the percentage was only 2.3 and 2.5 respectively. 1.5 percent could score a 29 while 0.6 percent scored a 30 and a 31.31 was the highest score scored by 0.6 percent of test-takers out of 466 . No test taker scored beyond 31 until up to 40 .

\section{Discussion of the Findings Related to the Research Question}

As discussed above, the research question dealt with whether the test takers found the three tests in the IHET difficult in both semesters and how they performed in the three skills in two semesters. To answer the research question, the researchers hypothesized that the 
IHET test takers found the three tests difficult in both semesters. As indicated in Figure 1 above, it was clear that the test takers' performance in the listening test in the first semester was so low that 14 percent scored a 0 while no candidate scored a 12 or beyond 12 despite the test consisting of 15 questions which should be attempted in 20 minutes, unlike the IELTS test which has 40 questions with 30 minutes without transfer time. If the percentage of zero scorers is converted into the number of students out of the total number of testtakers (408), one will find that 57 students could not score a single mark for the listening test. Likewise, if the percentage of students who scored the highest marks (11 out of 15), is converted into the actual number of students out of the total number of test-takers, one may find that only 8 students out of 406 could score 11 marks out of 15 in the listening text.

Figure 4 indicates the results of the listening test in the second semester and a comparison of the statistics between semester one and two results showed that the number of test-takers increased in the second semester (466) from (408) in the first semester. 37 students out of 466 scored a 0 in the listening exam while 9 students could score a 9 , but no student scored beyond 9. The statistical information indicated that test-takers did not perform well in the listening test in IHET in both semesters.

In terms of reading as shown in Figure 2, it is evident that test-takers did not perform well in the reading test too. Out of 408 test-takers, 44 students scored a 0 for reading while 8 students scored 13 marks out of 15 and no student got marks beyond 12 . When it comes to the second semester, the situation in reading seems to have gotten worse because 46 students scored a 0 while 9 students scored a 9 out of 15 , and no student scored beyond 9 in the reading exam in the second semester.

Unlike other skills (speaking, listening, and writing), students in this college generally spend more time on reading. Excluding the time spent at school studying English, these students have already spent 4 semesters in the foundation program with roughly 568 hours of studying reading and another 4 semesters in the post foundation program. Despite all this, students' performance in reading remained low below the expected level.

Concerning the results of writing in IHET, it needs to be stated that 28 students out of 408 scored 0 out of 40 marks while 3 students scored a 29 and no student scored beyond 29 in the first-semester exam. In the second semester, 32 students out of 466 scored a 0 out of 40 and 3 students scored a 31 indicating the highest score in the IHET in the second semester. When comparing the writing scores in the first semester with that of the second, it was evident that the number of zero scores was greater in the second semester than in the first. Overall results of both IHET indicated that there was no improvement in test takers' performance on all three skills. Given the low performance of the test-takers in both semesters, the researchers were prompted to explore whether the test-takers found the IHET difficult and it is to this dimension the researchers now turn.

As noted above, to investigate the linguistic difficulties experienced by test-takers, the researchers conducted a survey questionnaire in which the test takers were asked to rate how they answered questions in three tests. According to the results of the survey, $48 \%$ found listening difficult while only $4 \%$ found the test easy. In terms of reading, 30\% 
recorded that reading was difficult while $14 \%$ found it easy and writing was the most difficult of the three tests where $42 \%$ recorded that it was difficult while $18 \%$ found it easy. Moreover, skill-wise item analysis in listening further indicated that only $35 \%$ of the test takers agreed that they understood the main idea and specific factual information in the monologue and dialogue while $65 \%$ disagreed indicating that they did not understand. When it comes to reading, 37\% agreed that the reading texts were easy for them to read and understand the main idea. However, $63 \%$ found the reading texts difficult. Concerning writing tasks, $65 \%$ did not know how to organize an argument essay while $35 \%$ agreed that they know how to organize an argument essay. When asked about using cohesive devices and transition words/phrases, $73 \%$ said that they did not use cohesive devices or transition words/phrases in their essay. In the same task, 67 percent of the test takers reported that they did not pay attention to spelling, grammar, and punctuations while writing, whereas $33 \%$ agreed that they paid attention to the above aspects.

Part 2 of the questionnaire sought to find out ways and means through which the ELC could help test takers perform better in the IHET. 83\% strongly agree that ELC should conduct IHET preparation classes while 17\% remained neutral. Another statement was that ELC should select a few teachers who are proficient in providing test takers with academic advice on the three specific skills (Listening/Reading and Writing), 83\% strongly agreed with the idea and only $17 \%$ remained neutral. When asked about conducting a mock IHET exam and providing feedback before the actual exam, $86 \%$ agreed that a mock exam should be conducted, and feedback should be provided before the actual test while $14 \%$ neither agreed nor disagreed. The last statement in part 2 was that the ELC should make the past IHET test papers available to the eligible test-takers was responded with a higher percentage of strong agreement where $97 \%$ agreed on the idea while only $3 \%$ remained neutral

As noted above in the research instrument, qualitative analysis of the writing answer scripts against the writing rubrics (Task response, Coherence and cohesion, Lexical Resources, and Grammatical Range and Accuracy) was done. In task response, 43 (89\%) test-takers out of 48 failed to formulate and develop a position about a given statement, and their supporting ideas were not based on evidence and experience. Concerning coherence and cohesion, it was found that 42 test-takers neglected using cohesive devices to link ideas logically so that their essays lacked overall clarity. In terms of lexical resources, the researcher found 40 test-takers had problems with using a range of vocabulary relevant to the writing task while grammatical range and accuracy seemed to have posed a big problem to all candidates in that their essays were full of linguistic errors.

\section{Discussion of the Findings Related to the Survey}

As is clear from the findings of the survey questionnaire, the test takers found all three tests challenging in general. Without understanding the main idea and specific factual information in a monologue and a dialogue that students listen to in any listening test, the test takers cannot perform well to receive good scores for it. In addition, speaker's accent and unknown vocabulary can greatly matter when it comes to understanding and sorting 
out the required information and respond (In case of a listening test, candidates are asked to put a tick, underline or encircle the correct answer selecting from multiple options, writing one word/ a number) within the given period. Meanwhile, several students found accent and vocabulary difficult to comprehend. Regarding reading, most students found reading texts beyond their scope and a condition of this nature deprived the students of recognizing the writer's opinion, attitude, and purpose of the text. Furthermore, the readers must follow the development of an argument which an author makes in his/her writing to make meaning out of the text. As Goodman (1967) has observed that reading is a psycholinguistic guessing game, a process in which readers sample the text, make hypotheses, confirm or reject them, make new hypotheses, and so forth. The results of the questionnaire indicate that the test-takers lacked such reading abilities or strategies to cope with reading texts in the IHET

Writing is another test which the test takers found challenging and cognitively demanding because the students had to write an argument essay in which they needed to either agree or disagree with the statement/issue given. Research tells us that writing is not an ability that can be developed once and then automatically deployed in new contexts. Rather, new kinds of writing demand new capabilities and understandings even as they build from previous learning (http://writing-speech.dartmouth.edu/philosophyaims/writing-dartmouth). According to Bell and Burnably (1984), writing requires the writer to demonstrate control of several variables simultaneously. In addition, writing, even in one's mother tongue, is a demanding multi-stage task, which calls upon several language abilities, on more general, cognitive, linguistic, and meta-cognitive abilities are also crucially important in the writing development of second/foreign language learners. As suggested by the authors above, writing in an L2 requires constant practice and training with a writing instructor who is skilled in academic writing for a considerable time before they become proficient in different types of academic writing. Given the context in which the test takers performed in IHET, it was evident that they did not receive any practice condition of this kind unarguably led most of the test takers to receive low marks for writing tests. Moreover, the results indicate that the specialized committee that is responsible for preparing the IHET has not done any analysis of the test items that testtakers find difficult to score in each skill for the past few years. As a result, the specialized committee does not know how test-takers fare in the test. This is a pathetic condition on the part of students who want to pursue their higher studies in their chosen specializations in one respect and on the other, it is a gross violation of student rights in that they are deprived of access to higher education. This kind of activity will have negative consequences to the society in which they live and to the country in several ways. With this background information, we now discuss the possible reasons why a considerable number of students fail in the IHET below.

\section{Possible Reasons for the Low Performance of the Test Takers}

One of the possible reasons why the test takers fail to perform well in the IHET can mainly be ascribed to the fact that the construct of the IHET test and the curricula of the 
courses which the post-foundation students study at the colleges of technology do not perfectly match. Moreover, the IHET test is not designed to test a specific specialization (Engineering, IT, or Business Studies). Another reason is that the test takers lack proper training or adequate practice in listening, reading and writing skills. Seyabi and Tuzlukova (2014) report that Omani students complete their secondary school education with higher grades ranging from $\mathrm{C}+$ to $\mathrm{A}$. However, they enter higher education institutions with poor writing skills. While confirming what these researchers have stated in their study, we argue that most Omani students enter higher education institutions with low proficiency in all four skills. Once the students leave the general foundation program, they receive a chance to study English in the post foundation program in which they are supposed to study Technical Writing 1 \& 11, Technical Communication and Public Speaking. However, while studying in the post foundation, students do not receive any chance to study of what they will be tested in the IHET. By the time they sit for the IHET, they will have forgotten all what they studied in the general foundation program in two years back. We believe that a condition of this type may have been different if the test takers had been trained for this specific exam. Another possible factor why test takers find the IHET difficult is that IHET poses irrelevant cognitive barriers for the test takers' performance (Schroeder, 2016). The researchers have observed that most test-takers cannot understand the instruction in the test papers. Therefore, they cannot answer the questions properly. This mostly happens in writing. As shown in Figures 2, 5, and 6, a considerable number of test-takers have scored a 0 for all the three skills (listening, reading, and writing) and this is good proof that the test takers are incapable of understanding the questions properly before they attempt to answer them.

\section{Suggestions and Recommendations}

Based on the findings of the current research, the researchers wish to make the following suggestions and recommendations

1). Abolish the current In-House Entry Test and design, develop and pilot a suitable entry test that is fair for the post-foundation students in the colleges of technology.

2). Make a detailed analysis of the test results of all the seven colleges of technology for the span of at least 3 years and make the findings available to the public.

3). Start a systematic training program that will help post-foundation students to improve their language skills to a good level that is demanded in the entry test in every college.

4). Dissolve the current specialized committee based in Higher College of Technology and form a new specialized committee with qualified and competent lecturers representing all the seven colleges.

\section{Conclusion}

In conclusion, this paper reports the findings of a study that investigated why a clear majority of test-takers show low performance in three language skills (listening, reading, 
and writing) offered in the IHET in both semesters. The study included the analysis of the IHET results for two semesters, a questionnaire, and a qualitative analysis of writing answer scripts and findings indicated that most test takers were not qualified enough to pursue their studies in an advanced diploma or bachelor's degree programs. The findings, moreover, suggested that the current IHET test which is used by the colleges of technologies needs to be revised in line with the guidelines proposed in the ETS International Principles of the Fairness of Assessment issued by Educational Testing Service to make IHET a fair and valid test for test-takers. In addition, some of the possible reasons for the failure of the test takers were discussed and suggestions and recommendations for addressing the issue of the In-house entry test at the college level are offered.

\section{About the Authos:}

Sarath Withanarachchi Samaranayake is an English lecturer at the Department of International Language Teaching, Silpakorn University, Thailand. He received his doctoral degree in General Linguistics from the University of South Africa. He has published several articles in peer-reviewed international journals. His interests include teaching and researching in the domains of ESL and EFL. ORCid ID: https://orcid.org/0000-0002$6352-726 \mathrm{X}$

Patteera Theienpermpool (Ph. D) is a lecturer at the Department of International Language Teaching, Silpakorn University, Thailand. Her major interests concern vocabulary, material development, testing and evaluation as well as technology in language education. ORCid ID: https://orcid.org/0000-0002-9049-2912

\section{References}

Arrigoni, E., \& Clark, U. (2015). Investigating the appropriateness of IELTS cut-off scores for admission and placement decisions at an English medium university in Egypt. IELTS Research Report Online Series, 3(1-29).

Bellingham, L. (1993). The Relationship of language proficiency to academic success for international students. New Zealand Journal of Education Studies, 30(2), 229-232.

Bell, J., \& Burnaby, B. (1984). A handbook for ESL literacy. Toronto: Ontario Institute for Studies in Education Press.

Breeze, R., \& Miller, P. (2011). Predictive validity of the IELTS Listening Test as an indicator of student coping ability in Spain. IELTS Research Report Volume 12, 134.

Dörnyei, Z. (2007). Research Methods in Applied Linguistics. Oxford: Oxford University Press.

Elola, I. (2005). The complexity of revision in an intermediate-level Spanish language classroom and the creation of a foreign language revision model. Texas: University of lowa.

English Language Center. (2016). Annual Report of 2016. Shinas College of Technology. 
Oman. English Language Center (ELC). (n.a.). In-house Entry Test. Retrieved from http://www.shct.edu.om/content/house-entry-test

English Language Magazine. (2016). How to prepare for the test. Retrieved from https://www.shct.edu.om/english-magazine-2016

Expatriates must meet skill storage (2014, October 19), Oman Daily Observer. Retrieved from http://2016.omanobserver.om/expatriates-must-to-meet-skill-shortage/

Goodman, K. (1967). Reading: A psycholinguistic guessing game. Journal of the Reading Specialist, 6, 126-135. https://doi.org/10.1080/19388076709556976

IELTS. (2000). The IELTS handbook. Cambridge: Cambridge University Press.

Laerd Statistics (n.d.). Purposive Sampling. Retrieved from http://dissertation.laerd.com/ purposive-sampling.php

Larsen-Freeman, D. (1978). An ESL index of development. TESOL Quarterly, 12(4), 439448. https://doi.org/10.2307/3586142

Onwuegbuzie, A. J., \& Leech, N. L. (2007). A call for qualitative power analyses. Quality \& Quantity, 41, 105-121. https://doi.org/10.1007/s11135-005-1098-1

Schroeder, G. (2016). ETS International Principles for the Fairness of Assessment: A manual for developing locally appropriate guidelines for various countries. Educational Testing Service.

Times of Oman. (2016). Retrieved from http://timesofoman.com/article/93017/Oman/ Education/Oman-education: -More-than-10000-students-dropped-out-of-collegeslast-academic-year

Philips, D. (1990). Overseas students and their impact on the changing face of professional education in universities: A Paper presented at the Annual Conference of Australian Association for Research in Education (AARE). Sydney University.

Professional Testing Inc. (2006). How do you differentiate if a test has validity, reliability, fairness, and legal defensiveness? Retrieved from http://www.proftesting.com/test_topics/pdfs/test_quality.pdf

Seyabi, F. A., \& Tuzlukova, V. (2014). Writing problems and strategies: An investigative studyin the Omani school and university context. Asian Journal of Social Sciences and Humanities, 3(4), 37-48.

Shaw, S. (2006). IELTS Writing: Revising assessment criteria and scales (conclusion). Research Notes. University of Cambridge ESOL Examinations, 24, 19-22.

Taylor, L. (2004). Second language writing assessment: Cambridge ESOL's ongoing research agenda in Research Notes, 16, 2-3.

Wait, I., \& Gressel, J. (2009). Relationship between TOEFL score and academic success for international engineering students. Journal of Engineering Education, 98, 389398. https://doi.org/10.1002/j.2168-9830.2009.tb01035.x

Wolfe-Quintero, K., Inagaki, S., \& Kim, H.Y. (2001). Second language development in Language Acquisition, 23(3). Cambridge: Cambridge University Press 